\title{
A Transformed Eulerian Mean Diagnostics for a Sun-Weather Relation
}

\author{
By Yukio Misumi* \\ Geophysical Institute, Kyoto University, Sakyo-ku, Kyoto 606, Japan \\ (Manuscript received 4 October 1984, in revised form 25 November 1985)
}

\begin{abstract}
The aim of this study is to find a linkage of atmospheric responses to the solar sector boundary (SSB) passages (Wilcox et al., 1974; Misumi, 1981; 1983). Variations of both zonal mean fields and planetary waves around the SSB passages are investigated using the transformed Eulerian mean (TEM) equations system including the refractive index. Deviations from the time mean field in 8 winters from 1964 to 1972 are mainly discussed.

It is found that the Eliassen-Palm (EP) flux for zonal wavenumber 2 and 3 in the troposphere begins to decrease about 5 days prior to SSB passages. Such decrease leads to the divergence of the EP flux near the tropopause in high latitudes. This is responsible for the temperature decrease in the polar troposphere, and consequently for the decrease of the vorticity area index in the upper troposphere. The decreases of the EP flux for both wavenumber 2 originating from the troposphere and wavenumber 1 being at the $150 \mathrm{mb}$ level on 4 days before the SSB passages seem to create the minimum of the polar temperature in the middle stratosphere.

Among above mentioned processes, only the decrease of the EP flux is not diagnosed by the TEM equations system. The decrease of the EP flux in the troposphere is statistically significant and is seen only in the same period that other atmospheric responses occur. This type response would be due to the external modulation.
\end{abstract}

\section{Introduction}

The study of atmosphric dynamics respondent to the solar sector boundaries (SSB) passage was carried out by Wilcox et al. (1974; hereafter referred to as W74). They pointed out that the vorticity area index (VAI) defined by Roberts and Olson (1973) had a minimum on the first day after each SSB passage in the winters of 1964-1970. Wilcox et al. (1976) obtained the same result for the extended winters of 1963-1974. Hines and Halevy (1977) supported this kind of response from a satistical point of view.

Pittock and Shapiro (1982) reexamined those results and questioned about the reality of such response to the SSB passage. The es-

\footnotetext{
* Present affiliation Sendai District Meteorological Observatory.
}

sence of their criticism consists of two points ; (1) The VAI is an artificial parameter. No response of physical parameters such as the kinetic energy and absolute vorticity was found (Bhatnager and Jakobsson, 1978; Williams, 1978; Williams and Gerety, 1980). (2) The reported VAI response itself can not be found before 1963 or after 1973. (Williams and Gerety, 1978; Shapiro, 1979; Arora and Padgaonkar, 1981)

Recently, Misumi (1983; hereafter referred to as M83) analyzed zonal mean temperature and height on 7 pressure levels below the $100 \mathrm{mb}$ level in the Northern Hemisphere and found that the temperature in the polar troposphere reached a minimum on each SSB passage. Though this occurred in a limited area, the magnitude of the response was extremely significant in 8 winters (Dec., Jan., and Feb.) 
from 1964 to 1972 . Misumi (1981; hereafter referred to as M81) also reported minimum temperature in the polar middle stratosphere on 2.5 day after the SSB passages in the same winters. Since temperature is a fundamental parameter, these results answer Pittock and Shapiro's criticism (1). It should be mentioned that on VAI response to the geomagnetic storm is seen for longer period than that to the SSB passages (Arora and Padgaonkar, 1981). However, that response to geomagnetic storm is not so significant in a statistical view. Therefore, we should investigate more significant sun-weather relation.

M83 suggested that the dominant cause of the temperature response might be a dynamical process attributed mainly to the planetary wave. The transformed Eulerian mean formulation was introduced in order to describe wave-mean flow interactions by Andrews and McIntyre (1976; 1978). The Eliassen-Palm (EP) flux is included in this formulation. Its magnitude represents the wave activity and its direction shows the direction of the group velocity of the wave (ex. Edmon et al., 1980). In this paper wave-mean flow interactions around the SSB passages and their correlations to the reported responses are analyzed using both the transformed description by Andrews and McIntyre and the refractive index by Matsuno (1970).

\section{Data and formulation}

\subsection{Data}

The data used in this study are almost the same with those by both M81 and M83. Zonal Fourier components of geopotential height and temperature are obtained from the NMC gridpoint data at 10 pressure levels; $850,700,500,300,200,150,100,50,30$ and $10 \mathrm{mb}$. They cover from $20^{\circ} \mathrm{N}$ to the North Pole at $5^{\circ}$ latitude intervals for the period of 1964 to 1982 . The data below the $100 \mathrm{mb}$ level are at 12 hour intervals, but those above the $50 \mathrm{mb}$ level are at 1200 GMT at 24 hour intervals.

The data are arranged to be data of 12 hour intervals by interpolation with the quad- ratic function. Dates of the SSB passages are the same as M83. Those after 1979 are obtained by satellites observations. The method of superposing every SSB event on a key data is the same as M83.

\subsection{Formulation}

Following Palmer (1981, 1982) and Kanzawa (1982), the TEM formulation are expressed by,

$$
\begin{aligned}
& \frac{\partial \bar{u}}{\partial t}-f \bar{V}=D F \\
& \frac{\partial \bar{\theta}}{\partial t}=-\bar{\theta}_{z} \bar{W}+\bar{D} \\
& \frac{1}{\cos \phi} \frac{\partial}{\partial y}(\cos \phi \bar{V})+\frac{1}{p}-\frac{\partial}{\partial z}(p \bar{W})=0
\end{aligned}
$$

where

$$
\begin{aligned}
\bar{V}= & \bar{v}-\frac{1}{p} \frac{\partial}{\partial z}\left(p-\frac{\overline{v^{\prime} \theta^{\prime}}}{\bar{\theta}_{z}}\right) \\
\bar{W}= & \bar{w}+\frac{1}{\cos \phi} \frac{\partial}{\partial y}\left(\cos \phi \frac{\overline{v^{\prime} \theta^{\prime}}}{\bar{\theta}_{z}}\right) \\
D F= & \frac{1}{p \cdot a} \cdot \overline{\cos \phi} \nabla \cdot \boldsymbol{F}=p \frac{1}{p \cdot \overline{a \cdot \cos \phi}} \\
& \cdot\left\{\frac{1}{\cos \phi} \frac{\partial}{\partial y}\left(\cos \phi F_{y}\right)+\frac{\partial}{\partial z}\left(F_{z}\right)\right\} \\
\boldsymbol{F}= & \left(F_{y}, F_{z}\right)=p \cdot a \cdot \cos \phi\left(-\overline{u^{\prime} v^{\prime}}, f \frac{\overline{v^{\prime} \theta^{\prime}}}{\bar{\theta}_{z}}\right)
\end{aligned}
$$

(see Appendix A for undefined terms).

$\bar{V}$ and $\bar{W}$ are the residual mean meridional circulation and $\boldsymbol{F}$ is the Eliassen-Palm (EP) flux. This definition of EP flux is simple even though the dimension is not correctly written. If this EP flux divided by $\mathrm{RT}_{s}$ it is EP flux for unit volume (Kanzawa, 1982), and if by $p_{s}$ it is EP flux for unit mass (Palmer, 1982).

The relation between $D F$ and the residual mean meridional circulation is expressed by

$$
\left(f^{2} \frac{\partial^{2}}{\partial z^{2}}+N^{2}-\frac{\partial^{2}}{\partial y^{2}}\right) \varphi=f \frac{\partial D F}{\partial z}+\frac{\partial}{\partial y} \bar{D}(8)
$$

where $\varphi$ is a stream function for $(\bar{V}, \bar{W})$. This equation indicates that a residual mean meridional circulation appears when $\partial D F / \partial z$ $\neq 0$.

In this study, the basic field is defined as 
a time average over the range of \pm 15 days before and after each SSB passage. Hereafter, a basic field of a physical parameter $A$ will be denoted by $[A]$ and a deviation from it by $A^{\circ}$. In the first approximation, the following relations should be hold

$-f[\bar{V}]=[D F]$

$-\left[\bar{\theta}_{z} \bar{W}\right]+[\bar{D}]=0$

$\frac{1}{\cos \phi} \frac{\partial}{\partial y}(\cos \phi[\bar{V}])+\frac{1}{p} \frac{\partial}{\partial z}(p[\bar{W}])=0$

Hence eqs. (1), (2), (3) and (8) are rewritten as

$$
\begin{aligned}
& \frac{\partial \bar{u}}{\partial t}-f \bar{V}=\frac{\partial \bar{u}^{\circ}}{\partial t}-f \bar{V}^{\circ}=D F^{\circ} \\
& \frac{\partial \bar{\theta}}{\partial t}=\frac{\partial \bar{\theta}^{\circ}}{\partial t}=-\left(\bar{\theta}_{z} \bar{W}\right)^{\circ}+\bar{D}^{\circ} \\
& \frac{1}{\cos \phi} \frac{\partial}{\partial y}\left(\cos \phi \bar{V}^{\circ}\right)+\frac{1}{p} \frac{\partial}{\partial z}\left(p \bar{W}^{\circ}\right)=0 \\
& \left(f^{2} \frac{\partial^{2}}{\partial z^{2}}+N^{2}-\frac{\partial^{2}}{\partial y^{2}}\right) \varphi^{\circ}=f \frac{\partial D F^{\circ}}{\partial z}+\frac{\partial}{\partial y} \bar{D}^{\circ}
\end{aligned}
$$

These equations indicate that the time variation can be estimated by deviations from the basic field.

Unless otherwise stated, our results are based on 43 passages which occurred in 8 winters from 1964 to 1972 . Basic mean fields of this study were obtained by superposition of these 43 cases, which are discussed in Appendix B.

Furthermore, to examine the property of wave propagation, we will use 'refractive index' by Matsuno (1970);

$$
Q_{k}=\frac{\bar{q}_{y}}{\bar{u}}-\frac{k^{2}}{(a \cdot \cos \phi)^{2}}-\frac{f^{2}}{4 N^{2} H^{2}}
$$

where

$$
\begin{aligned}
\bar{q}_{y}= & -\frac{2 \Omega \cos \phi}{a}-\frac{\partial}{\partial y}\left\{-\frac{1}{\cos \phi}-\frac{\partial}{\partial y}(\bar{u} \cos \phi)\right\} \\
& +\frac{f}{p}-\frac{\partial}{\partial z}\left(-\frac{p \bar{\theta}_{y}}{\bar{\theta}_{z}}\right)
\end{aligned}
$$

Following Palmer (1981), the relation between $Q_{k}$ and $F$ is,

$$
\left\{f^{2}\left(F_{y}\right)^{2}+N^{2}\left(F_{z}\right)^{2}\right\}^{1 / 2}={ }_{2 f}^{p_{s}} Z_{k}^{2} \sqrt{Q_{k}}
$$

where $Z_{k}$ is the amplitude in zonal Fourier $k$-th component of the height field. $\boldsymbol{F}$ is guided along a ridge of $Q_{k} / f^{2}$.

We also use the following relationshig between $D F$ and the eddy quasi-geostrophic potential vorticity $\left(q^{\prime}\right)$ (Palmer, 1982)

$$
D F=\overline{v^{\prime} q^{\prime}}
$$

where

$$
\begin{aligned}
q^{\prime}= & \frac{\partial v^{\prime}}{\partial x}-\frac{f}{\cos \phi} \frac{\partial}{\partial y}\left(-\frac{\cos \phi}{f} u^{\prime}\right) \\
& +\frac{f}{p}-\frac{\partial}{\partial z}\left(p \frac{\theta^{\prime}}{\bar{\theta}_{z}^{-}}\right)
\end{aligned}
$$

as is given by Matsuno (1970). These equations are the TEM equations system.

\section{Results}

\subsection{Zonal mean field}

First the main results by M81 and M83 are summarized. Fig. 1 shows meridional cross sections of $\bar{u}^{\circ}$ for 12 days from Day -6 to Day 5 (where Day $n(-n)$ represents $n$th days after (before) the SSB passage). Characteristics of the time variations are listed below.

$\langle\mathrm{U} 1\rangle$ : In the vertical zone below the 30 mb level around $80^{\circ} \mathrm{N}, \bar{u}^{\circ}$ is accelerated eastward in the period from Day -4 to Day -0.5 (not shown) but decelerated after the SSB passages. This phenomenon has two centers : One at the $300 \mathrm{mb}$ level is named as $\langle\mathrm{U} 1 \mathrm{a}\rangle$ and the other at the $50 \mathrm{mb}$ and $100 \mathrm{mb}$ levels as $\langle\mathrm{U} 1 \mathrm{~b}\rangle$. As was already shown in Fig. 5 in M83, $\langle\mathrm{U} 1 \mathrm{a}\rangle$ holds the thermal wind balance to the temperature response which takes place in the polar troposphere. $\langle\mathrm{U} 1 \mathrm{~b}\rangle$ is also a reflection of the tropospheric temperature response but is a little modulated by some temperature changes within the lower stratosphere.

$\langle\mathrm{U} 2\rangle$ : At the $10 \mathrm{mb}$ level around $70^{\circ} \mathrm{N}, \bar{u}^{\circ}$ is accelerated in the period from Day 1 to Day 3, and decelerated after that. This variation must be related with the temperature change reported as a SSB response by M81.

$\langle\mathrm{U} 3\rangle$ : At $40^{\circ} \mathrm{N}$ around the $300 \mathrm{mb}$ level, the maximum of $\bar{u}^{\circ}$ occurs on Day -1.5 (not shown). This was pointed out in Fig. 4 in M83. 

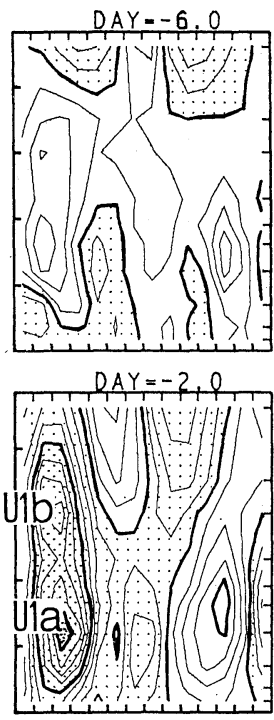

$D A Y=2,0$

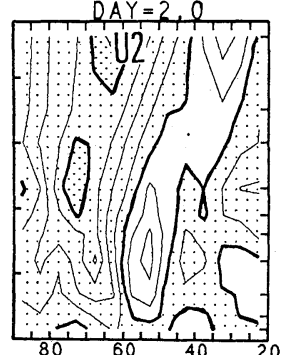

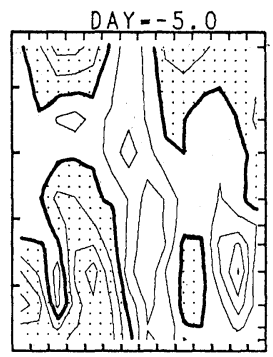

$D A Y=-1,0$

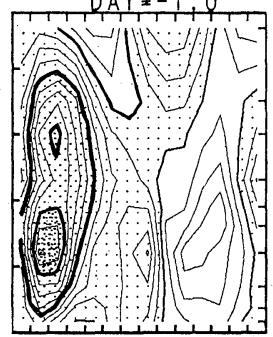

DAY - 3, 0

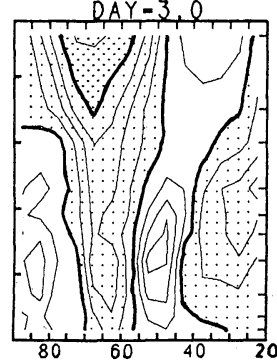

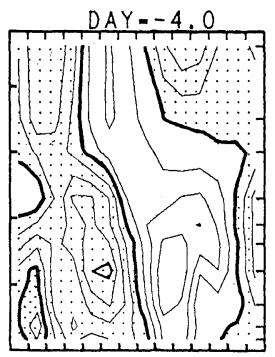

$D A Y=0,0$

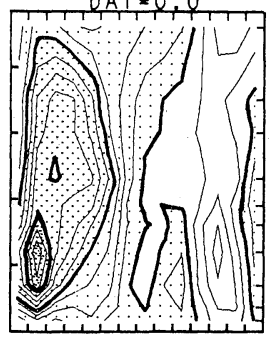

DAY $-4,0$

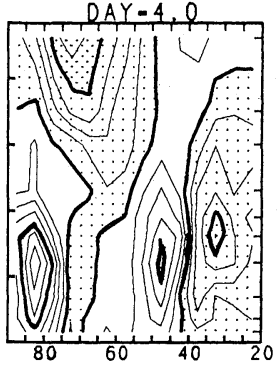

Latitude
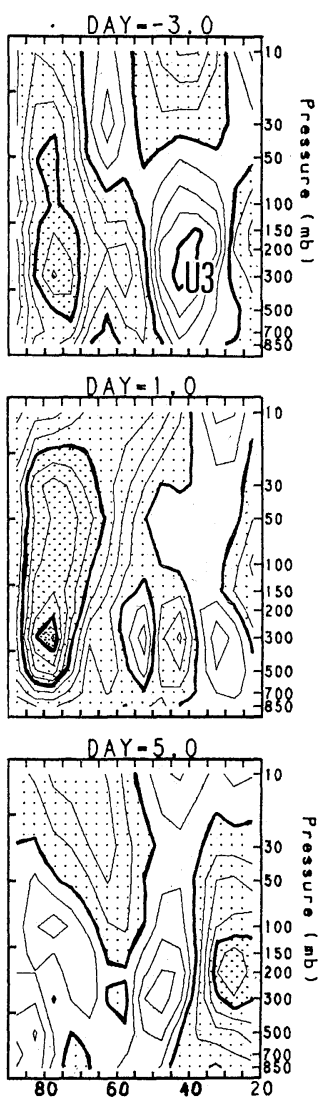

Fig. 1 Meridional cross sections of $\bar{u}^{\circ}$ for 12 days from Day -6 to 5 . The interval of contours is $0.25 \mathrm{~m} / \mathrm{s}$. Eastward anomaly regions are shaded. The name of each region is written in the text (3.1).

\subsection{Effects of waves on the zonal mean fields}

Fig. 2 shows meridional cross sections of $D F^{\circ}$ for zonal wavenumbers $(k) 1-3 . D F^{\circ}$ is connected to $\bar{u}^{\circ}$ through eq. (12). Waves shorter than those of $k=3$ are excluded because of their small contribution.

During 4 days from Day -5 to Day -2 , $D F^{\circ}$ keeps positive in the northern part of $50^{\circ} \mathrm{N}$ in the $200-500 \mathrm{mb}$ layer, this being named as $\langle$ Div. 1$\rangle$. The maximum of $\langle$ Div. 1$\rangle$ occurs in the $300-500 \mathrm{mb}$ layer between $65^{\circ}$ and $70^{\circ} \mathrm{N}$ on Day -4.5 (see Fig. 4(a)). The maximum area moves upward from Day -2 to Day -1 , this being named as $\langle$ Div. 2$\rangle$. Other regions where $D F^{\circ}>0$ appear around the $10 \mathrm{mb}$ level from Day -2 to Day 2 and in the $30-100 \mathrm{mb}$ layer around Day -3 . Those are named $\langle$ Div. 3〉 and $\langle$ Div. 4$\rangle$, respectively.

On Day 0 , negative $D F^{\circ}$ appears at $80^{\circ} \mathrm{N}$, this being named as $\langle$ Con. 1$\rangle$ and one at $60^{\circ} \mathrm{N}$ in the $200-300 \mathrm{mb}$ layer, as 〈Con. 2〉. On Day 1.5 (not shown) at the polar region in the layer $20-300 \mathrm{mb}$ is $\langle$ Con. 3〉. Though $\langle$ Con. 2〉 disappears soon, both $\langle$ Con. 1〉 and $\langle$ Con. 3〉 remain until Day 3. In the following sub-sections, mutual relations of $D F^{\circ}, \bar{u}^{\circ}$ and $\bar{T}^{\circ}$ will be discussed.

\subsubsection{EP flux divergences and merdional circulation}

$\langle$ Div. 1 1$\rangle$ and $\langle$ U1a $\rangle$ are grossly balanced with each other. However, the following two points seem to be unreasonable: One is that $\langle\mathrm{U} 1 \mathrm{a}\rangle$ is biased poleward from $\langle$ Div. 1$\rangle$ and the other is that top of $\langle\mathrm{Ula}\rangle$ spreads over 


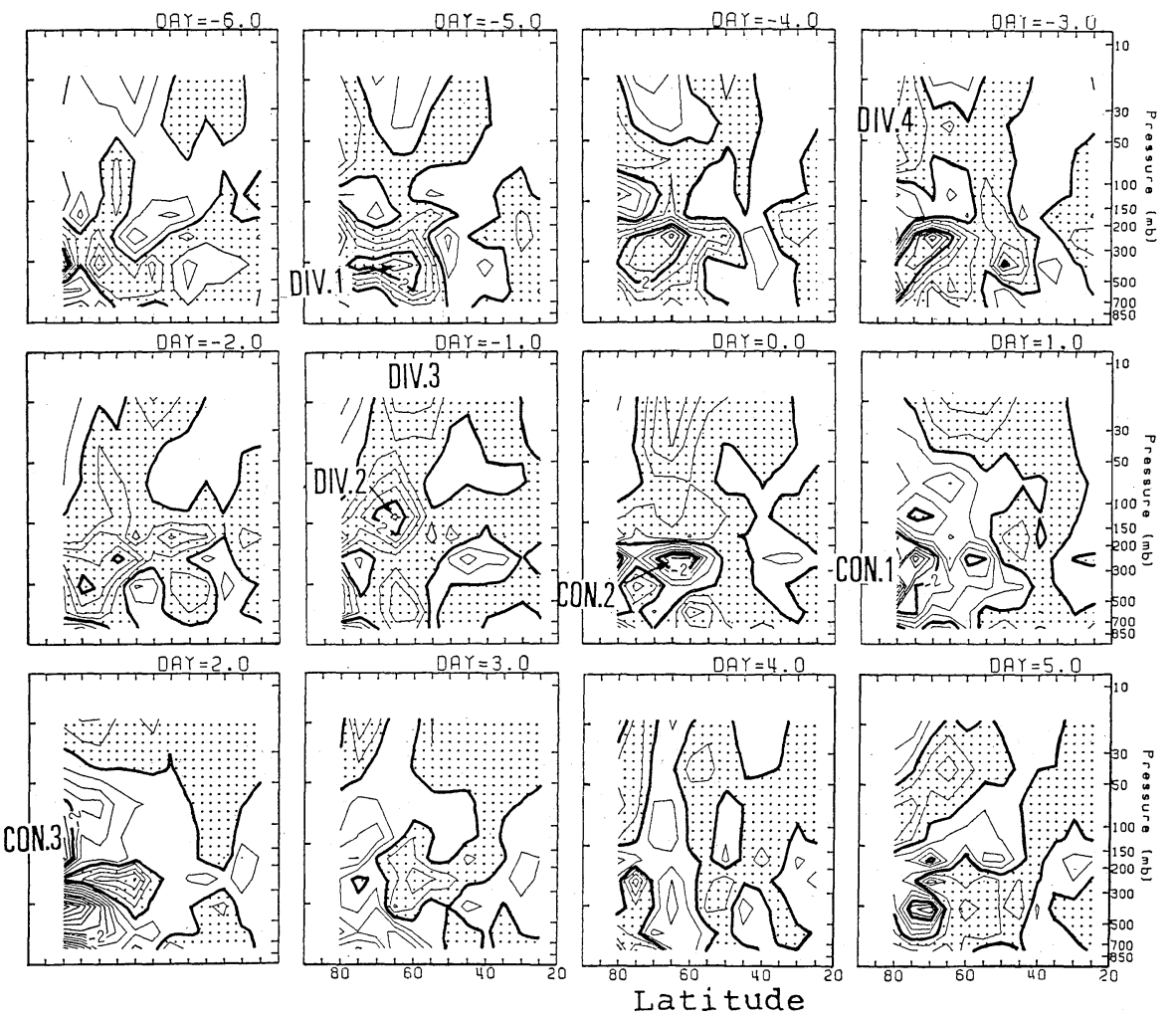

Fig. 2 Meridional cross sections of $D F^{\circ}$ for $k=1-3$ on the same days as Fig. 1. The interval of contours is $0.5 \mathrm{~m} / \mathrm{s} /$ day and thick contour is used where deviation is exceed $2.0 \mathrm{~m} / \mathrm{s} /$ day. The region where $D F^{\circ}>0$ is shaded. The name of each region is the same as in the text (3.2).

that of $\langle$ Div. 1$\rangle$. These can be explained as follows :

A schmatic cross section of the residual mean circulation $\left(\bar{V}^{\circ}, \bar{W}^{\circ}\right)$ expressing a wave mean flow interaction in the period of $\langle$ Div. 1$\rangle$ is shown in Fig. 3. The $A$ region is the center of 〈Div. 1〉. The eastward acceleration in the $\mathrm{C}$ region is greater than that in the $\mathrm{B}$ region, because $\bar{V}^{\circ}$ in the former is smaller than that in the latter. The westward acceleration due to the anticlockwise residual mean circulation is dominant in the $\mathrm{D}$ region. The temperature in the $\mathrm{E}$ region decreases because of the upward $\bar{W}^{\circ}$. The magnitude of $\bar{W}^{\circ}$, which is estimated from Fig. 4 (a) by eq. (14) with assumption of $\bar{W}^{\circ}=0$ at the tropopause, is almost the same as that of $\bar{W}^{\circ}$ estimated from temperature decrease in M83 by eq. (13) under assumption of $\bar{D}^{\circ}=0$.

The equatorward $\bar{V}^{\circ}$ region in the 150 $300 \mathrm{mb}$ layer to the south of $40^{\circ} \mathrm{N}$ shown in

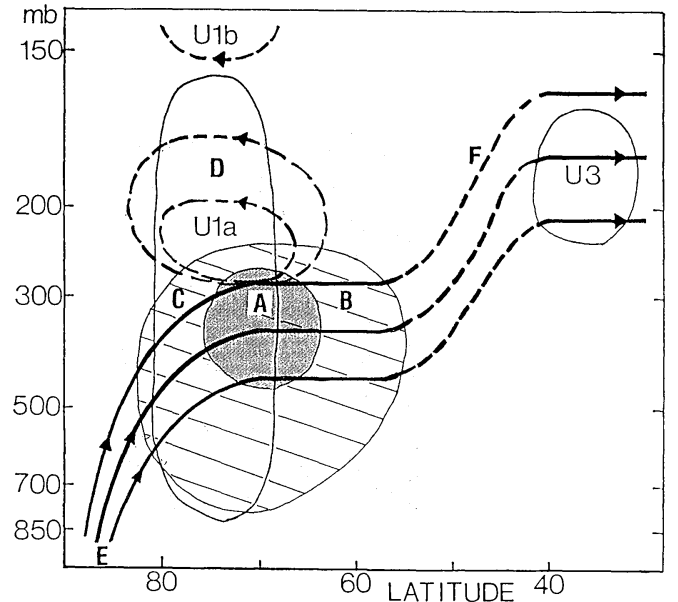

Fig. 3 A schematic meridional cross section of wave and flow activities in the period of $\langle$ Div. 1 $\rangle$. Thick line shows the residual mean circulation $\left(\bar{V}^{\circ}, \bar{W}^{\circ}\right)$. The region where $D F^{\circ}>0$ is hatched and enclosed by thin line and especially the region where $D F^{\circ} \gg 0$ is shaded. This region corresponds to 〈Div. 1$\rangle$. The $\langle\mathrm{U} 1 \mathrm{a}\rangle$ and $\langle\mathrm{U} 3\rangle$ region are also enclosed by thin line. The name of regions is seen in the text (3.2.1). 

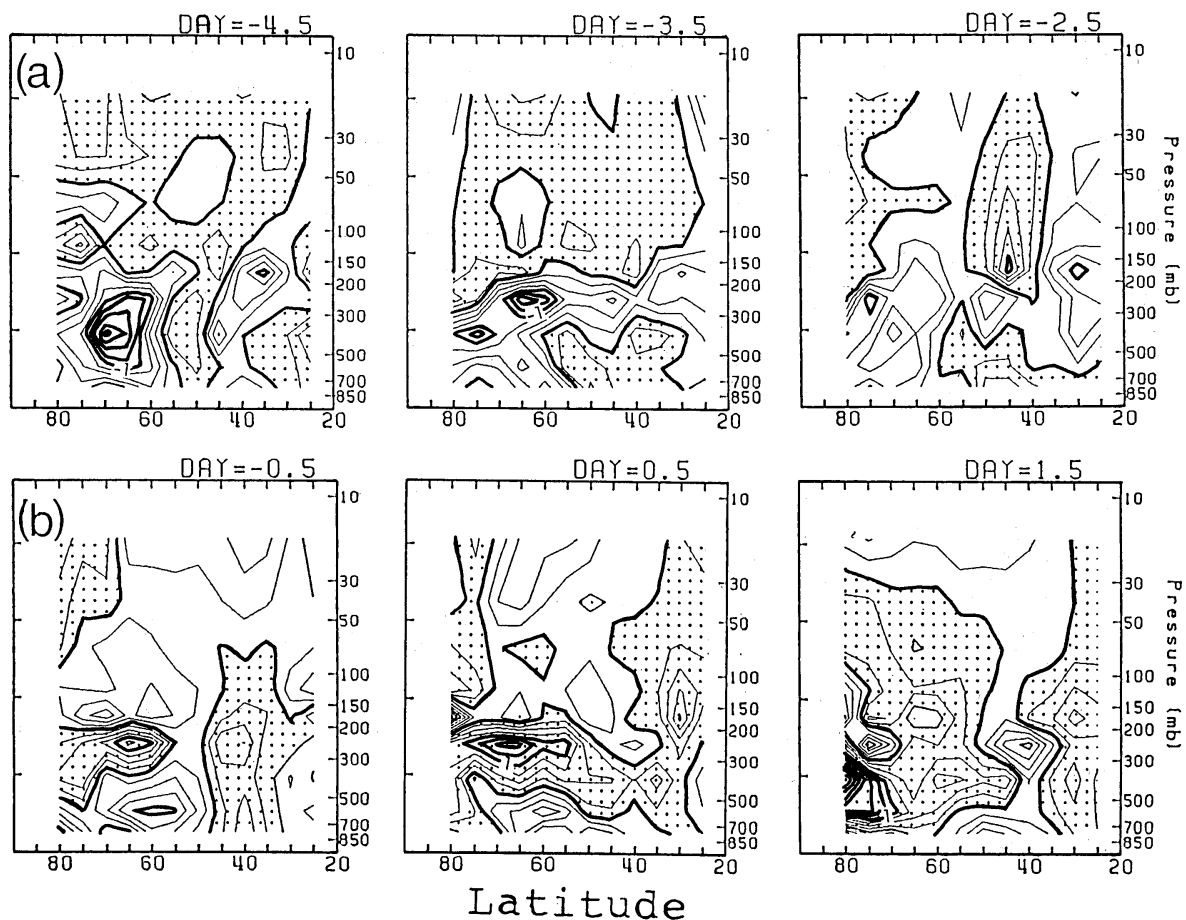

Fig. 4 Meridional cross sections of $f \bar{V}^{\circ}$ on Day $-4.5,-3.5$ and -2.5 (a) and on Day -0.5 , 0.5 , and 1.5 (b). This $\bar{V}^{\circ}$ is estimated as the residual term in eq. (12). The interval of contours is $0.25 \mathrm{~m} / \mathrm{s} /$ day. The region where $\bar{V}^{\circ}>0$ is shaded.

Fig. $4(\mathrm{a})$ is balanced with $\langle\mathrm{U} 3\rangle$. The upward $\bar{W}^{\circ}$ in the $\mathrm{F}$ region connecting the southward $\bar{V}^{\circ}$ in high latitudes and that in low latitudes is supposed by the temperature descent in the $150-200 \mathrm{mb}$ layer around $40^{\circ} \mathrm{N}$ (not shown). These show that all variations of $\bar{u}$ and $\bar{T}$ before the SSB passages is mutually related to $\langle$ Div. 1$\rangle$. Moreover, the circulation pattern in Fig. 3 is just as the same as the reverse of the basic residual mean circulation shown in Appendix B. This implies that the basic residual mean circulation is weakened by $\langle$ Div. 1$\rangle$.

$\langle$ Div. 4$\rangle$ is expected to affect $\langle\mathrm{U} 1 \mathrm{~b}\rangle$. However, any correlations of the position and the magnitude between $\langle\mathrm{U} 1 \mathrm{~b}\rangle$ and $\langle\mathrm{Div} .4\rangle$ are not clear, merely because the center of $\langle$ Div. $4\rangle$ lies out of the frame (see 3.4.2). 〈Div. 2〉 spreads $\langle\mathrm{U} 1 \mathrm{~b}\rangle$ to the south and $\langle$ Div. 3$\rangle$ must create $\langle\mathrm{U} 2\rangle$.

\subsubsection{EP flux convergences}

Fig. 4 (b) shows the same cross sections as Fig. 4(a) except for those around Day 0 .
Maxima of poleward $\bar{V}^{\circ}$ take place over those

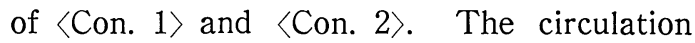
reverse to the circulation shown in Fig. 3 can be expected in polar and high latitudes. The downward part of this reverse circulation must be responsible for the increase of the temperature in the polar troposphere after Day 0 (M83).

$\langle\mathrm{U} 1 \mathrm{a}\rangle$ is cancelled out by $\langle$ Con. 1$\rangle$, and $\langle\mathrm{U} 1 \mathrm{~b}\rangle$ by $\langle$ Con. 3$\rangle$. An interesting point is that the cancellation drifts $\langle\mathrm{U} 1 \mathrm{a}\rangle$ and $\langle\mathrm{U} 1 \mathrm{~b}\rangle$ equatorward. In the case $\langle$ Con. 1$\rangle$ and $\langle\mathrm{U} 1 \mathrm{a}\rangle$ are overlapped, the south part of $\langle\mathrm{U} 1 \mathrm{a}\rangle$ becomes a new $\langle\mathrm{U} 1 \mathrm{a}\rangle$ ridge, because the westward acceleration center due to $\langle$ Con. 1$\rangle$ is biased poleward due to the meridional asymmetry of $\bar{V}^{\circ}$. In addition to that, the wide drift of $\langle\mathrm{U} 1 \mathrm{a}\rangle$ needs that of $\langle$ Con. 1$\rangle$, which will be discussed in 3.4.3. As expected by eq. (15), 〈Con. 3$\rangle$ should result in upward $\bar{W}^{\circ}$ in the polar stratosphere, which is related to the temperature decrease there (M81). The phenomenon which counteracts $\langle\mathrm{U} 2\rangle$ is not found in Fig. 2. 


\subsection{EP flux convergence and the VAI response}

Both the position and time of 〈Con. 2〉 accord with those of descent of the VAI (W74). A relationship between $D F^{\circ}$ and the eddy geostrophic potential vorticity flux, as is indicated by eq. (19), is that the eddy potential vorticity is transferred to the south when $D F^{\circ}<0$. The absolute vorticity used to define the VAI is closely related to the potential vorticity. Any modulation of the potential vorticity by $D F^{\circ}$ could be responsible for the VAI variation. Moreover, this modulation does not conflict with results from some researchers (Bhatnagar and Jakobsson, 1978; Williams, 1978; Williams and Gerety, 1980) using variations of the kinetic energy or the total squared vorticity.

\subsection{Variations of EP flux}

\subsection{1 〈Div. 1〉}

Fig. 5 (a) shows meridional cross sections of $\boldsymbol{F}^{\circ}$ and $D F^{\circ}$ for $k=1-3, k=1, k=2$, and $k=3$ on Day -4.5 when $\langle$ Div. 1$\rangle$ is at the maximum. It is found that $\langle\mathrm{Div} .1\rangle$ consists of $D F^{\circ}$ for $k=2$ and $k=3$ and is independent of $D F^{\circ}$ for $k=1$. Fig. 5 (a) shows that both the contributions are caused by decreases of $F_{z}$ for $k=2$ and $k=3$ around Day -5 in the troposphere, which are shown as $\langle\mathrm{P} 2\rangle$ in Fig. 6(b) and $\langle\mathrm{P} 3\rangle$ in Fig. 6(c), respectively. $\langle\mathrm{P} 2\rangle$ of which the center is at $55^{\circ} \mathrm{N}$ in the $300-$ $500 \mathrm{mb}$ layer develops to Day -3.5 , and $\langle\mathrm{P} 3\rangle$ of which the center is at $60^{\circ} \mathrm{N}$ below the 850 $\mathrm{mb}$ level develops to Day -4 . Both phenomena create negative $F_{z}{ }^{\circ}$ regions on the meridional plane, and this region moves up- (b)
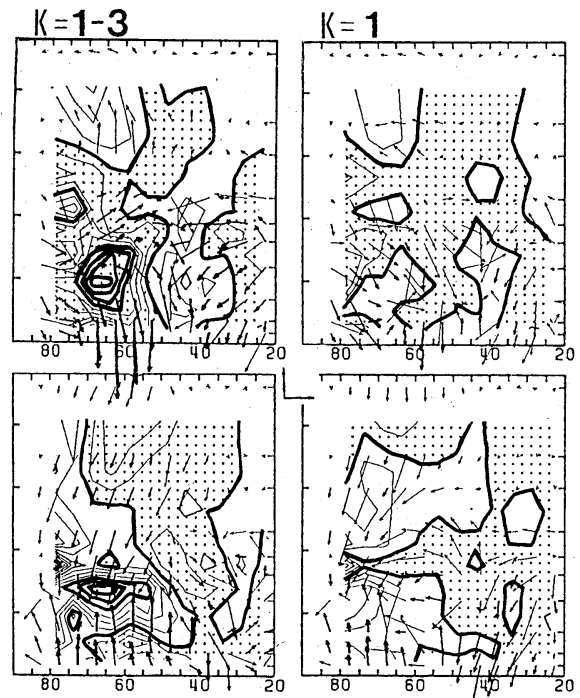

(c)
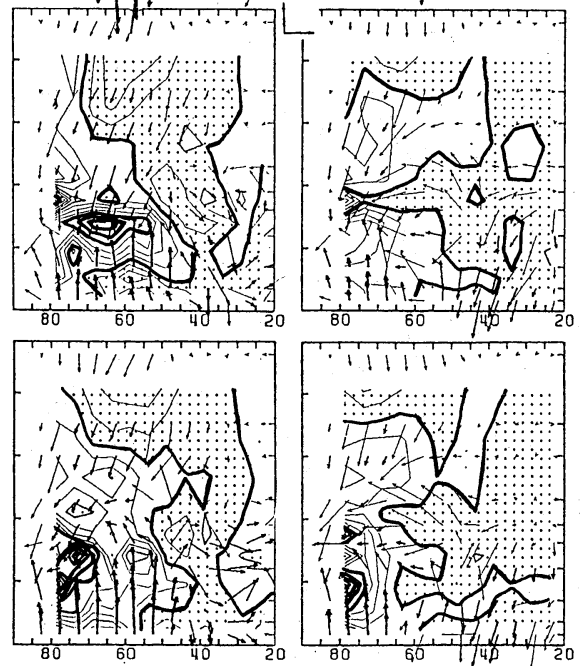
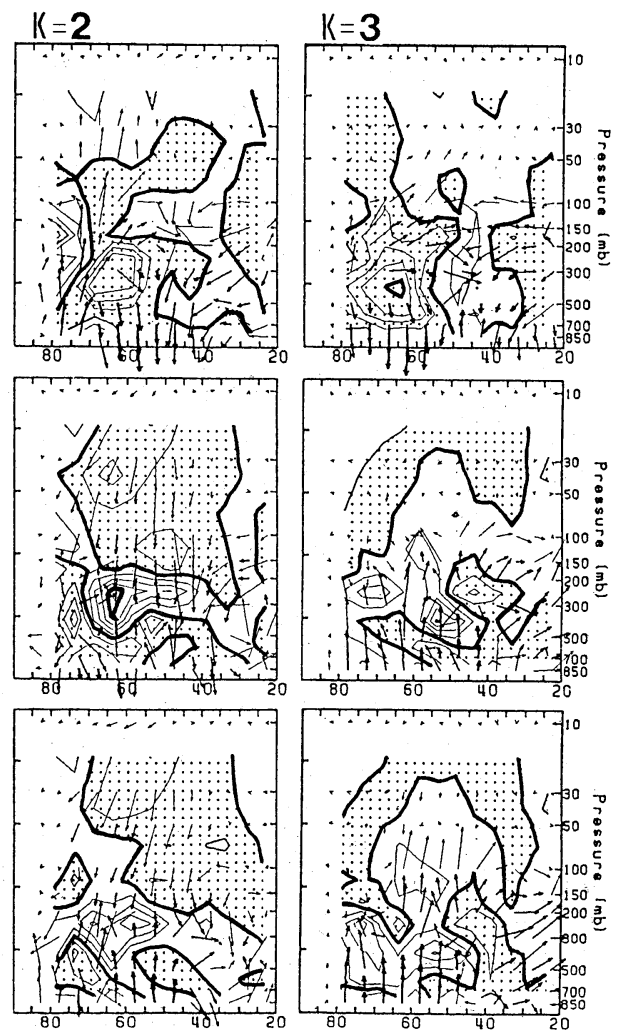

LATITUDE

Fig. 5 Meridional cross sections of $F^{\circ}$ and $D F^{\circ}$ for $k=1-3,1,2$, and 3 on Day -4.5 (a), Day 0.5 (b) and Day 1 (c). The meridional (vertical) arrow at the middle upper-left represents a value of $F_{y}\left(F_{z}\right)$ equal to $5.21 * 10^{14}\left(1.96 * 10^{12}\right) \mathrm{kg} \cdot \mathrm{m} \cdot \mathrm{s}^{-2}$. 

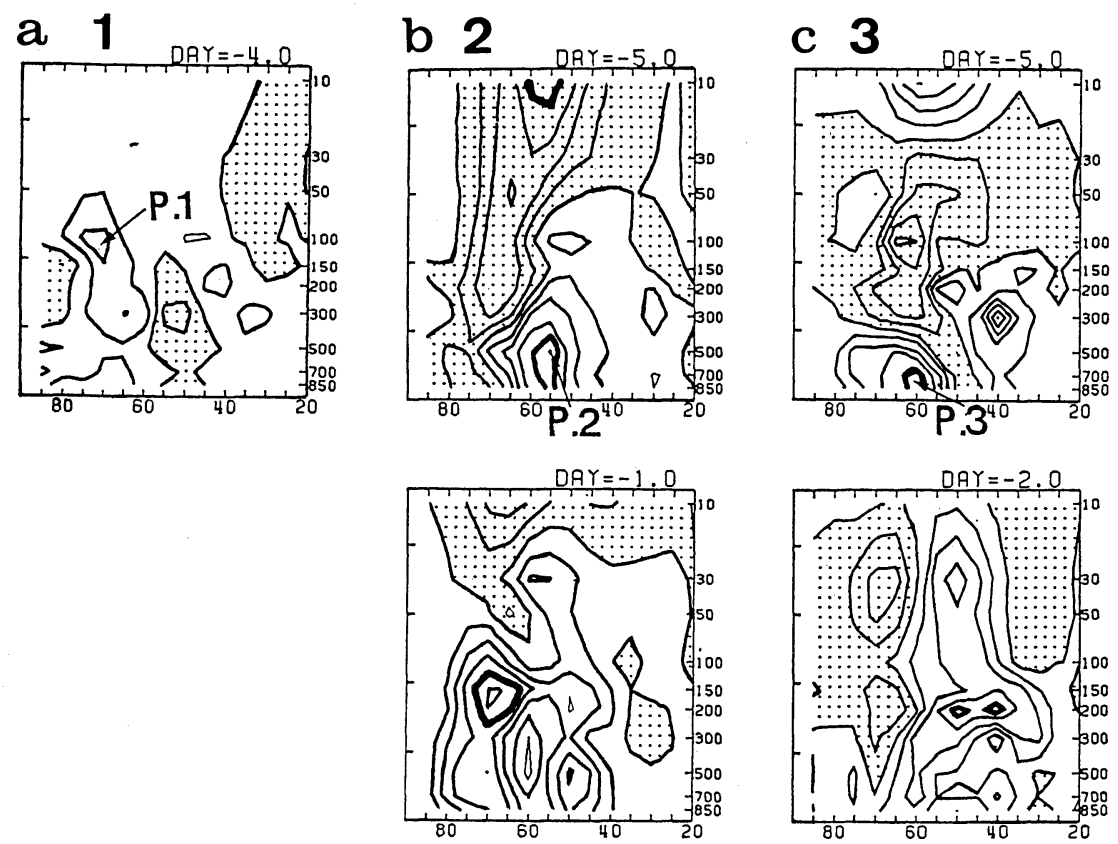

Fig. 6 Meridional cross sections of normalized $F_{z}$ for $k=1$ (a), $K=2$ (b), and $k=3$ (c). The normalized $F_{z}$ is defined by dividing $F_{z}{ }^{\circ}$ by an average value of $\left[F_{z}\right]$ at each level. The interval of contours is 0.25 , and positive regions are shaded. $\langle\mathrm{P} 1\rangle,\langle\mathrm{P} 2\rangle$ and $\langle\mathrm{P} 3\rangle$ are discussed in the text.

ward into the stratosphere by wave propagations (shown in Fig. 6(b) and (c)). Therefore, $\langle$ Div. 1〉 must be caused by the passage of this negative $F_{z}{ }^{\circ}$ region through the upper troposphere, namely the transiency of the wave, because the value of $\partial F_{z}^{\circ} / \partial z$ at a confined level becomes positive in the time when the negative $F_{z}{ }^{\circ}$ region approaches to there. This is expected from the fact that 〈Div. 1〉 disappears when the minimum of $F_{z}$ caused by $\langle\mathrm{P} 2\rangle$ and $\langle\mathrm{P} 3\rangle$ reaches the tropopause (on Day -3 for $k=2$ and Day -2.5 for $k=3$ ).

\subsubsection{Other divergent regions}

$\langle$ Div. 2〉 is caused by the passage of the negative $F_{z}{ }^{\circ}$ region due to $\langle\mathrm{P} 2\rangle$. In this case the contribution of $k=2$ is dominant, while $\boldsymbol{F}$ of $k=3$ tends to turn to the equatorward around the tropopause (see Appendix B).

$\langle$ Div. 3〉 is produced by the passage of the negative $F_{z}{ }^{\circ}$ region for $k=1$ in the first phase from Day -1.5 to 0 . Fig. 6 (a) shows that this structure is due to $\langle\mathrm{P} 1\rangle$ that $F_{z}$ for $k=1$ is reduced in the $100-150 \mathrm{mb}$ layer around $70^{\circ} \mathrm{N}$ from Day -4 to Day -3 . After that the negative $F_{z}{ }^{\circ}$ for $k=2$ due to $\langle\mathrm{P} 2\rangle$ reaches there and takes over the contributions of $k=1$ to $\langle$ Div. 3〉 until Day 3.

$\langle$ Div. 4 $\rangle$ is probably due to $\langle\mathrm{P} 1\rangle$, because waves in $\langle$ Div. 4$\rangle$ comes through the $\langle\mathrm{P} 1\rangle$ region (see Fig. 11(c) in Appendix B). However, this is not confident, because the meridional finite difference scheme used to calculate $F_{y}{ }^{\circ}$ and $\partial F_{y}{ }^{\circ} / \partial y$ have large errors in the polar region*1.

\subsection{3〈Con. 1$\rangle$}

Fig. 5 (c) shows that $\langle$ Con. 1$\rangle$ is due to $\boldsymbol{F}$ for $k=1$ amplified and tilted the poleward in the troposphere. The increasing $\boldsymbol{F}$ for $k=1$ does not propagate into the polar stratosphere (not shown) and both maxima of 〈Con. 1〉 and that of $F_{z}$ for $k=1$ occurs on the same data on Day 2. These facts suggest that 〈Con. 1〉 is mainly created by the dispersion of the wave.

This increase of $\boldsymbol{F}$ for $k=1$ can be diag-

*1 However, we can discuss about 〈Div. 1〉 and $\langle$ Con. 1〉, because they are free from what meridional finite difference scheme is used. 

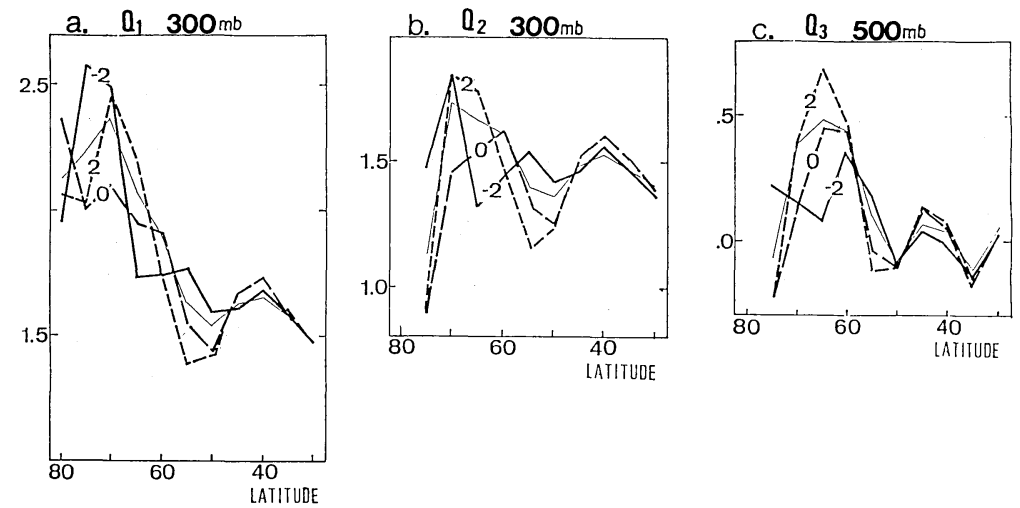

Fig. 7 (a) Latitudinal distributions of $Q_{1}$ at the $300 \mathrm{mb}$ level on Day -2 , 0 and 2. (b) Same as (a), but for $Q_{2}$ at the $300 \mathrm{mb}$ level. (c) Same as (a), but for $Q_{3}$ at the $500 \mathrm{mb}$ level. The vertical scale is $10^{-12} \mathrm{~m}^{-2}$. The number on the line shows day from the SSB passage. Thin line is the basic field.

nosed by Fig. 7 (a) which shows the latitudinal structure of the refractive index for $k=1\left(Q_{1}\right)$ at the $300 \mathrm{mb}$ level (About the calculation error of $Q_{1}$ in the polar region, see 3.4.5). Under normal conditions, $Q_{1}$ at the $300 \mathrm{mb}$ level has the maximum at $70^{\circ} \mathrm{N}$, where $\boldsymbol{F}$ for $k=1$ passes through from the troposphere to the stratosphere. Around Day 0, this maximum is moved poleward by the eastward wind ridge at $80^{\circ} \mathrm{N}$ corresponding to $\langle\mathrm{U} 1 \mathrm{a}\rangle$. Therefore, the direction of $\boldsymbol{F}$ for $k=1$ becomes poleward. Since $Q_{1}$ in the polar stratosphere is negative (not shown), the increasing $\boldsymbol{F}$ for $k=1$ in the polar troposphere is dispersed and creates $\langle$ Con. 1$\rangle$. Together with the center of $\langle\mathrm{U} 1 \mathrm{a}\rangle$ drifting equatorward shown in 3.2.2, this maximum of $Q_{1}$ returns to $70^{\circ} \mathrm{N}$ and then the direction of $\boldsymbol{F}$ of $k=1$ turns to the south. This clearly suggests that $\langle$ Con. 1〉 following $\langle\mathrm{U} 1 \mathrm{a}\rangle$.

\subsection{4〈Con. 2〉}

$\left\langle\right.$ Con. 2〉 is due to $F_{z}$ for $k=2$ and $k=3$, as is seen in Fig. 5(b). The contribution of $F_{z}$ for $k=2$ locates in the $200-300 \mathrm{mb}$ layer and that for $k=3$ in the $300-500 \mathrm{mb}$ layer. On Day $-0.5, F_{z}$ for $k=2$ at the $300 \mathrm{mb}$ level begins to increase, when that at the $200 \mathrm{mb}$ level remains small (not shown). Its spatial variation gives rise to $\langle$ Con. 2$\rangle$. Unlike $\langle$ Con. 1), 〈Con. 2〉 disappears when $F_{z}$ for $k=2$ reaches its maximum. As mentioned in 3.4.1, this temporal relation suggests that $\langle$ Con. 2$\rangle$ is generated by the transiency of the wave.

The variation of $F_{z}$ for $k=2$ can be accounted for by $Q_{2}$. Fig. 7 (b) shows the latitudinal structure of $Q_{2}$ at the $300 \mathrm{mb}$ level. Just before Day 0 , the peak of $Q_{2}$ at $70^{\circ} \mathrm{N}$ disappears because of $\langle\mathrm{U} 3\rangle$. After Day 0 , this peak rappears and develops to Day 2 with some reduction of $\langle\mathrm{U} 3\rangle$. The same change of $Q_{2}$ also occurs at the $500 \mathrm{mb}$ level, but not at the $200 \mathrm{mb}$ level (not shown). Therefore, $F_{z}$ for $k=2$ increases below the $300 \mathrm{mb}$ level and then $\partial F_{z}^{\circ} / \partial z$ become negative in the 200$300 \mathrm{mb}$ layer. 〈Con. 2$\rangle$ is related only to the magnitude of $Q_{2}$ peak, though $\langle$ Con. 1$\rangle$ is related to the position of $Q_{1}$ peak. Thus, the direction of $F$ for $k=2$ is independent of $\langle$ Con. 2〉: The dispersion of the wave is not great in $\langle$ Con. 2$\rangle$ unlike 〈Con. 1$\rangle$, and the duration of $\langle$ Con. 2$\rangle$ is shorter than that of 〈Con. 1〉 (see 3-2). The contribution of $\boldsymbol{F}$ for $k=3$ to $\langle$ Con. 2$\rangle$ is the same as that of $F_{z}$ for $k=2 . Q_{3}$ at the $500 \mathrm{mb}$ level behaves similarly as $Q_{3}$ (see Fig. 7(c)), but that at the $300 \mathrm{mb}$ level does not (not shown), because the second term of $Q_{3}$ shown in eq. (16) is much larger than that of $Q_{2}$ in high latitudes. Therefore, in the case of $k=3$, the minimum of $D F^{\circ}$ occurs in the $300-500 \mathrm{mb}$ layer.

\subsection{5〈Con. 3〉}

As already mentioned in $3.4 .2, F_{y}$ in the 

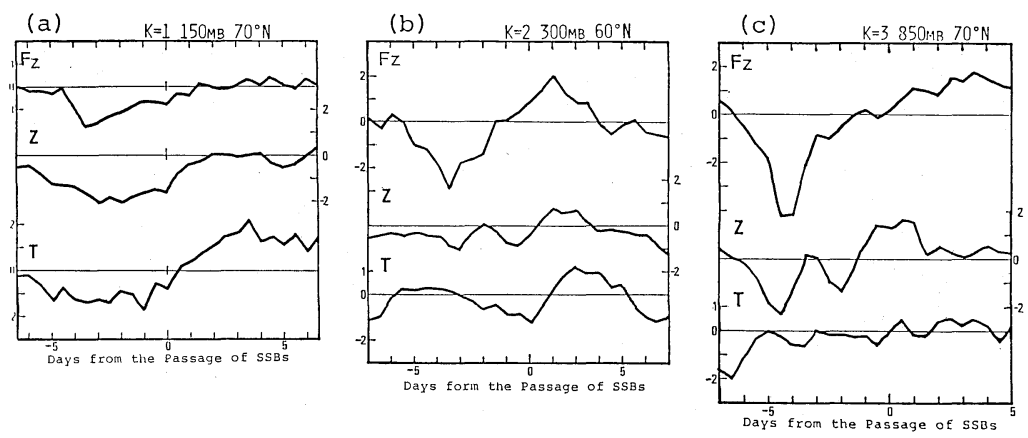

Fig. 8 Variations of $t$-value of $F_{z}^{\circ}$, of the amplitude of wave with respect to height $(H)$ and temperature $(T)$ for $k=1$ at the $150 \mathrm{mb}$ level at $70^{\circ} \mathrm{N}$ (a), for $k=2$ at the $300 \mathrm{mb}$ level at $60^{\circ} \mathrm{N}$ (b), and for $k=3$ at the $850 \mathrm{mb}$ level at $70^{\circ} \mathrm{N}$ (c).

〈Con. 3〉 region can not be estimated. $Q_{k}$ in the 〈Con. 3〉 region also includes much larger errors generated by the meridional finite difference scheme than that in the $\langle$ Con. 1〉 region, because the former is more biased to the pole than the latter and the meridional difference term of eq. (17), i.e., $\frac{\partial}{\partial y}\left\{\frac{1}{\cos \phi} \frac{\partial}{\partial y}(\bar{u} \cos \phi)\right\}$, is dominant in the former, as is shown in Fig. 10 in Appendix B. Hence, it is meaningless to diagnose 〈Con. 3〉 by the distribution of $Q_{k}$.

\section{Discussions}

The dynamical processes after $\langle\mathrm{P} 1\rangle,\langle\mathrm{P} 2\rangle$, and $\langle\mathrm{P} 3\rangle$ have been discussed by use of the TEM equations system. We will discuss about $\langle\mathrm{P} 1\rangle,\langle\mathrm{P} 2\rangle$, and $\langle\mathrm{P} 3\rangle$ in the following. The magnitude of $\langle\mathrm{P} 1\rangle,\langle\mathrm{P} 2\rangle$, and $\langle\mathrm{P} 3\rangle$ in the 8 winters of 1964-1972 are extremely larger than other winters in the period of 1964-1982 (not shown). This indicates that the decrease of EP flux plays an essential role in the reported responses (W74, M81 and M83).

The refractive indices $Q_{2}$ and $Q_{3}$ in the troposphere around Day -5 (not shown) have not such variations as those around Day 0 shown in Fig. 7. This implies that $\langle\mathrm{P} 2\rangle$ and $\langle\mathrm{P} 3\rangle$ can not be diagnosed by the TEM equations system.

The statistical significance of these phenomena is analysed. Fig. 8 shows variations of Student's $t$ value of $F_{z}$ for $k=1$ at the 150 $\mathrm{mb}$ level at $70^{\circ} \mathrm{N}$ (a), for $k=2$ at the $300 \mathrm{mb}$ level at $60^{\circ} \mathrm{N}(\mathrm{b})$, and for $k=3$ at the $850 \mathrm{mb}$ level at $70^{\circ} \mathrm{N}$ (c) around the SSB passages. These give an information about the statistical significance of $\langle\langle\mathrm{P} 1\rangle,\langle\mathrm{P} 2\rangle$, and $\langle\mathrm{P} 3\rangle:\langle\mathrm{P} 1\rangle$, of which $t$ value is -1.71 , is statistically meaningless. $\langle\mathrm{P} 3\rangle$ of -4.24 is significant.
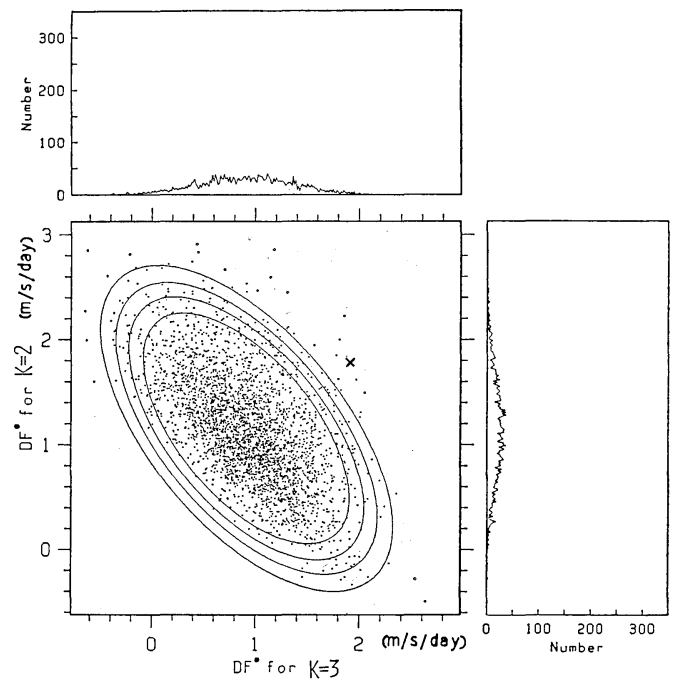

Fig. 9 Distributions of $3000\left(D F^{\circ}\right.$ for $k=3$ and $D F^{\circ}$ or $k=2$ ) at $70^{\circ} \mathrm{N}$ in the $200-500 \mathrm{mb}$ layer which constitute maxima of $D F^{\circ}$ for $k=2-3$ in the superposed result with \pm 15 days interval These superposes are performed by use of 43 key dates chosen randomly from the winters of 1964-1972 with more than 5 days intervals. 4 ellipses indicate $10 \%, 5 \%, 2.5 \%$, and $1 \%$ level of $\chi^{2}$ test respectively. The cross indicates the value of $D F^{\circ}$ for $k=2-3$ on Day -4.5. The EP flux used in this test is filtered by the same method as M83 to remove the seasonal trend. 
$\langle\mathrm{P} 2\rangle$ of -2.85 is hard to judge correctly from Fig. 8.

To study the significance level in more detail, we must use the so-called random sampling method (Haurwitz and Brier; 1981, and M83). Fig. 9 is a result for $\langle$ Div. 1$\rangle$. It shows that $\langle$ Div. 1$\rangle$ is beyond $99 \%$ confidence level, and both of the contribution of $k=2$ and 3 are effective for this confidence. Therefore, we should not exclude $\langle\mathrm{P} 2\rangle$ which is the origin of the contribution of $k=2$ for $\langle$ Div. 1$\rangle$.

Fig. 8 shows variations of $t$ value of the amplitude of wave with respect to height $(\mathrm{H})$ and temperature ( $\mathrm{T})$. These variations in $\langle\mathrm{P} 2\rangle$ the $\langle\mathrm{P} 3\rangle$ are much smaller than those of $F_{z}$. This fact is in accordance with the results by Williams and Gerety (1980) who found no significant variation in the kinetic and available potential energy of planetary waves. Therefore, $\langle\mathrm{P} 2\rangle$ and $\langle\mathrm{P} 3\rangle$ should be mainly responsible for the decrease of the westward inclination of wave phase for $k=2$ and 3 in the vertical. On the other hand, the variation in $\langle\mathrm{P} 1\rangle$ accompanies a comparable variation of the kinetic energy.

\section{Concluding remarks}

In this study, the interactions between zonal mean fields and planetary waves around the SSB passages are described by the TEM equations system together with the refractive index. The conclusions of this study are:

1. The EP flux for $k=2$ and 3 in the troposphere had decreased during a few days from 5 or 6 days before the SSB passages.

2. This phenomenon coincides with the atmospheric responses reported so far (Wilcox et al., 1974 ; Misumi, 1981 ; 1983).

3. However, this can not be diagnosed by the TEM equations system.

4. Not the change of the wave amplitnde but the westward inclination of the wave phase to the vertical direction is responsible for the phenomenon.

5. There is a possibility that EP flux for $k=1$ in the stratosphere decreases before the $\mathrm{SSB}$ passages.

The two questions remain to be solved:

1. In the sense of the sun-weather rela- tion, what can we consider from the fact that the response occurs on 5 days before the SSB passages?

2. Why does such a response occur only in the 8 winters limited from 1964 to 1972 ?

To approach these questions, Misumi (1986) has checked variations of some solar and interplanetary parameters around SSB passages, and found out that $10.7 \mathrm{~cm}$ solar radio flux intensity was smaller from 6 to 1 days before the SSB passages. This is a temporal variation limited in the same 8 winters as those used in this paper. This should be a key to the above questions. However, we do not easily understand a link between them. Any mechanism for that should be investigated in the future.

\section{Acknowledgement}

The author wishes to express his hearty thanks to Prof. I. Hirota of the Geophysical Institute of Kyoto University for his continuous guidance. He would like to thank Dr. H. Kanzawa of National Institute of Polar Research and Mr. M. Shiotani of the Geophysical Institute of Kyoto University for their helpful discussions about the TEM system, and Mr. Shirakawa for his help to print the manuscript. Finally, the author would like to express his sincere thanks to the editor and the referees whose careful comments to the improvement of the present manuscript. The computations were performed at the Data Processing Center of Kyoto University and of the National Institute of Polar Research.

\section{Appendix. A}

List of symbols.

$(u . v . w)$, zonal, meridional, and vertical component of geostrophic wind velocity.

$\phi$, latitude.

$\lambda$, longitude.

$\theta$, potential temperature.

$\Omega$, angular speed of rotation of the Earth.

$H$, constant scale height $(=7000 \mathrm{~m})$.

$R$, gas constant for dry air.

$f, \quad(2 \Omega \cdot \sin \phi)$ Corioli's parameter.

$p$, pressure in mbar.

$p_{s}$, surface pressure (1013.25 mbar).

$a$, radius of the Earth. 
$D$, diabatic heating.

$\Phi$, geopotential height.

$\bar{X}$, zonal mean of physical parameter $X$.

$X^{\prime}$, deviation of physical parameter $X$ from the zonal mean.

$N, \quad\left(=\left[\begin{array}{c}g \bar{\theta}_{z} \\ \bar{\theta}\end{array}\right]^{1 / 2}\right)$ Brunt-Väisälä frequency.

\section{Appendix. B}

The basic fields for the 43-case are discussed. These fields approximately correspond with the climatological mean field in the winters from 1964 to 1972, because they are the mean of 30 days around 43 key dates scattered all over 8 winters. Fig. 10 shows meridional cross sections of $[\bar{u}]$. It has good

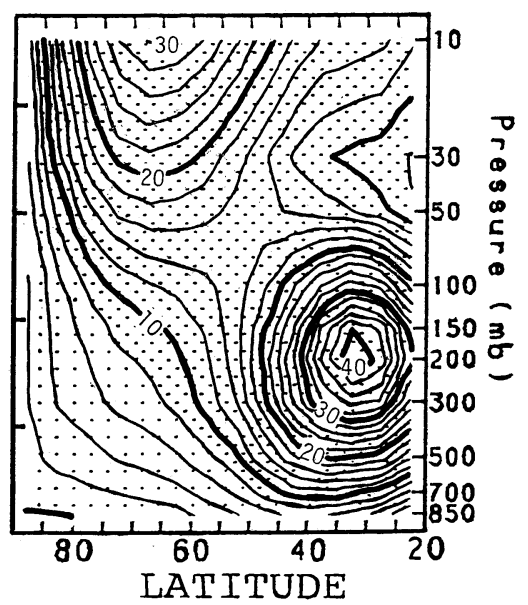

Fig. 10 Meridional cross section of $[\bar{u}]$. The interval of contours is $2 \mathrm{~m} / \mathrm{s}$. The eastward wind is shaded. accordance with other climatological means in winter. Fig. 11 shows $[\boldsymbol{F}]$ cross sections for $k=1-3$ (a), $k=1$ (b), $k=2$ (c) and $k=3$ (d). Some characters of these are listed as follows :

B-1. All waves are dispersed in the upper troposphere: The convergence center for $k=1$ is north of $80^{\circ} \mathrm{N}$, that for $k=2$ at $75^{\circ} \mathrm{N}$ and that for $k=3$ at $60^{\circ} \mathrm{N}$.

B-2. In the troposphere $[\boldsymbol{F}]$ for each of three wavenumbers is comparable, but $[\boldsymbol{F}]$ for $k=3$ is negligible small in the middle stratosphere, because most of it turns southward in the lower stratosphere.

B-3. The convergence or divergence of $[\boldsymbol{F}]$ must be equal to $-f[\bar{V}]$, see eq. (9). The pattern in Fig. 11(a) suggests the same residual mean circulation pattern as Fig. 6 of Edmon et al. (1980) and Fig. 3 of Karoly (1982), but the center of northward residual mean flow in the equatorial region seems to biased to the north from that of their results. The maximum northward velocity in high latitudes is about $0.7 \mathrm{~m} / \mathrm{s}$.

It must be noted that after 1972, [F] for $k=1$ directs to the south in the upper-north part of Fig. 11(b), and so the divergent region locates there.

\section{References}

Andrews, D. G. and M. E. McIntyre, 1976: Planetary waves in horizontal shear: the generalized Eliassen-Palm relation and the mean zonal acceleration. J. Atmos. Sci., 33, 2031-2048.

and - 1978: Generalized Eliassen-

Palm and Charney-Drazin theorems for waves on

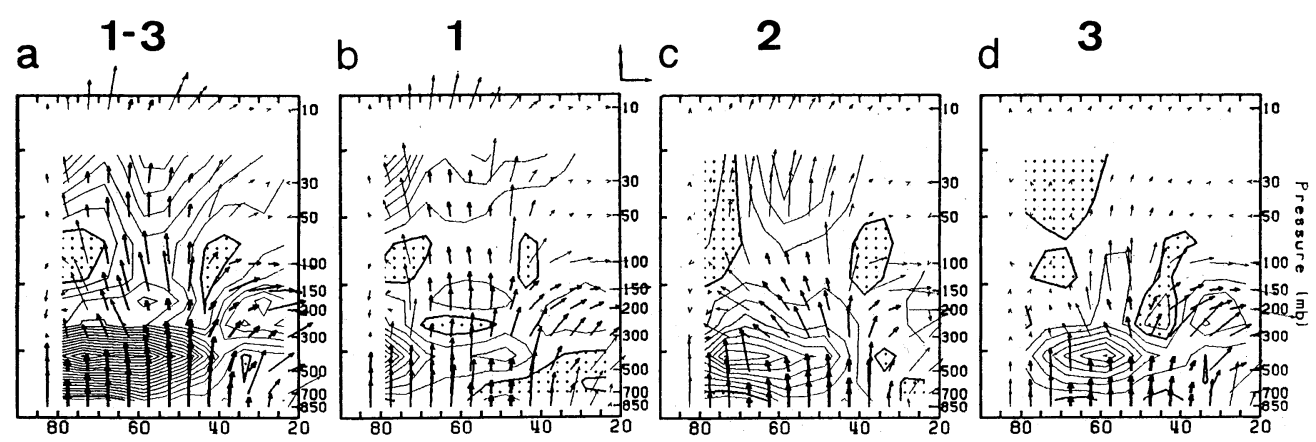

LATITUDE

Fig. 11 Meridional cross sections of $[\boldsymbol{F}]$ for $k=1-3$ (a), $k=1$ (b), $k=2$ (c), and $k=3$ (d). The meridional (vertical) arrow at middle upper-left represents a value of $F_{y} \cos \phi\left(F_{z} \cos \phi\right)$ equal to $2.09 * 10^{15}\left(7.84 * 10^{12}\right) \mathrm{kg} \cdot \mathrm{m} \cdot \mathrm{s}^{-2}$. The scale of the most thick arrow is 5 times greater than that of standard arrow, which is also 5 times greater than that of the thin arrow. 
axisymmetric means flows in compressible atmospheres. J. Atmos. Sci., 35, 175-185.

Arora, B. R. and A.D. Padgaonkar, 1981: Timevariation of solar influence on the tropospheric circulation. J. atmos. terr. Phys., 43, 91-95.

Bhatnagar, V.P. and T. Jakobsson, 1978: Lack of effects of solar magnetic sector crossings on the troposhere. Geophys. Res. Lett., 5, 180-182.

Edmon, H. J,, B. J. Hoskins and M.E. McIntyre, 1980 : Eliassen-Palm cross sections for the troposhere. J. Atmos. Sci., 37, 2600-2616.

Haurwitz, M. W. and G. W. Brier, 1981: A critique of the superposed epoch analysis method: its application to solar-wather relations. Mon. Wea. Rev., 109, 2074-2079.

Hines, C. O. and I. Halevy, 1977: On the reality and nature of a certain sun-weather correlation. J. Atmos. Sci., 34, 382-404.

Kanzawa, H., 1982 : Eliassen-Palm flux diagnostics and the effect of the mean wind on planetary wave propagation for an observed sudden stratosperic warming. J. Meteor. Soc. Japan, 60, 1063-1073.

Karoly, O. J., 1982: Eliassen-Palm cross section for the Northern and Southern Hemispheres. J. Atmos. Sci., 39, 178-182.

Matsuno, T., 1970: Vertical propagation of stationary planetary waves in the winter Northern Hemisphere. J. Atmos. Sci., 27, 871-883.

Misumi, Y., 1981: The reponse of the stratospheric temperature to the passage of solar sector boundaries. Paper presented at the meteorology and upper atmosphere. IAMAP Assembly, Hamburg, August, 1981.

- 1983: The tropospheric response to the passage of solar sector boundaries. J. Meteor. Soc. Japan, 61, 686-694.

- 1986: The external forcing of the atmospheric response to the solar sector boundary passage. J. Met. Soc. Japan, 64, 137-146.

Palmer, T.N., 1981: Aspects of stratospheric sudden warmings studied from a transformed Eulerian-mean viewpoint. J. Geophys. Res., 86, 9679-9687.

, 1982: Properties of the Eliassen-Palm flux for planetary scale motions. J. Atmos. Sci., 39, 992-997.

Pittock, A. B. and R. Shapiro, 1982: Assessment of evidence of the effect of the solar variations on weather and climate. Solar Variability, Weather, and Climate, p 64-75, National Academic Press Washington D. C..

Roberts, W. O. and R.H. Olson, 1973: Geomagnetic storms and wintertime 300-mbar trough development in the North Pacific North America area. J. Atmos. Sci., 30, 135-140.

Shapiro, R., 1979: An examination of certain proposed sun-weather connections. J. Atmos. Sci., 36, 1105-1116.

Wilcox, J. M., P.H. Scherrer, L. Svalgaard, W. O. Roberts, R.H. Olson and R. L. Jenne, 1974 : Influence of solar magnetic sector structure on terrestrial atmospheric vorticity. J. Atmos. Sci., 31, 581-588.

- L. Svalgaard and P.H. Scherrer, 1976: On the reality of a sun-weather effect. J. Atmos. Sci., 33, 1113-1116.

Williams, R.G., 1978: A study of the energetics of a particular sun-weather relation. Geophys. Letts., 5, 519-522.

- and E. J. Gerety, 1978: Does the troposphere respond to day-to-day changes in solar magnetic field? Nature, 275, 200-201.

and - 1980: A further study of the troposheric energetics of a particular sunweather relation. J. atmos. terr. Phys., 42, 2734.

\title{
変換したオイラー万程式系で見た太陽活動と気象の関係
}

\author{
三角幸 夫* \\ 京都大学理学部地球物理学教室
}

惑星間空間磁場境界通過に対する地球大気の応答として報告されている現象 (Wilcox et al., 1974; Misu$\mathrm{mi}, 1981 ， 1983)$ の原因と関連を調べた。惑星規模の力学過程に注目して屈折指数を含んだ変換したオイラー (TEM) 方程式を用いて解析した。以下 1964-1972年間の北半球の冬における季節平均場からの偏差について 議論している。

東西波数 2 と 3 成分の EP フラックスが通過 5 日前頃から高緯度対流圈において減少していた。この減少に よって通過前 4.5 0.5 日間に高緯度の対流圈界面付近でE-Pフラックスの発散が起り, 次にこの発散は極域対 流圏の温度を減少させ, 又 Vorticity Area Index の減少を引き起こす。さらに波数 2 の EPフラックスの減 少は, $150 \mathrm{mb}$ 面付近で通過 4 日前に始まる波数 1 成分の EP フラックスの減少と相まって成層圈極域にお护 る温度極少の原因になった。

以上の過程で EP フラックスの減少のみが TEM 方程式系で説明できない。特に対流圏内の EP フラック スの減少は統計的に有意でしかも他の応答と同じ期間にしか見出されない。

* 現在：仙台管区気象台 